\title{
Serratus plane block anesthesia for breast surgery and local anesthetic
}

toxicity: a case report

Lugo C.; Juez A.; Armelles E.; Jiménez R. HOSPITAL UNIVERSITARIO 12 DE OCTUBRE, MADRID (SPAIN)

INTRODUCTION
We describe a case of local anesthethic toxicity (LAST) due to a fascial plane block intended as anesthethic technique for breast
surgery in a patient with cardiac morbidity.

\section{CASE DESCRIPTION}

Female, 41YO, scheduled to bilateral extraction of breast prosthesis due to spontaneous ruptura.

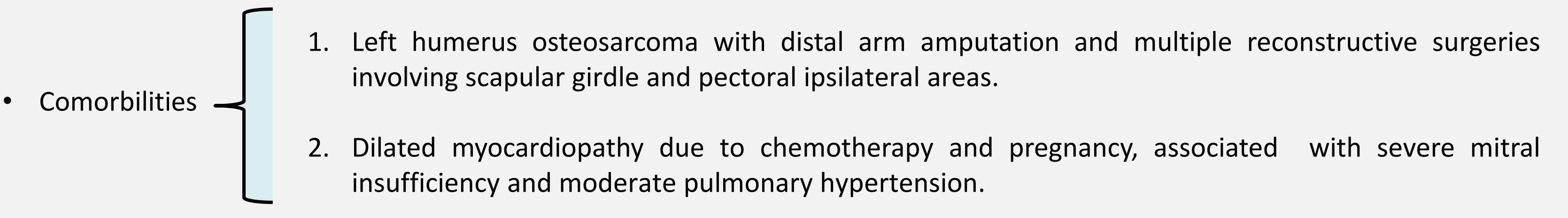

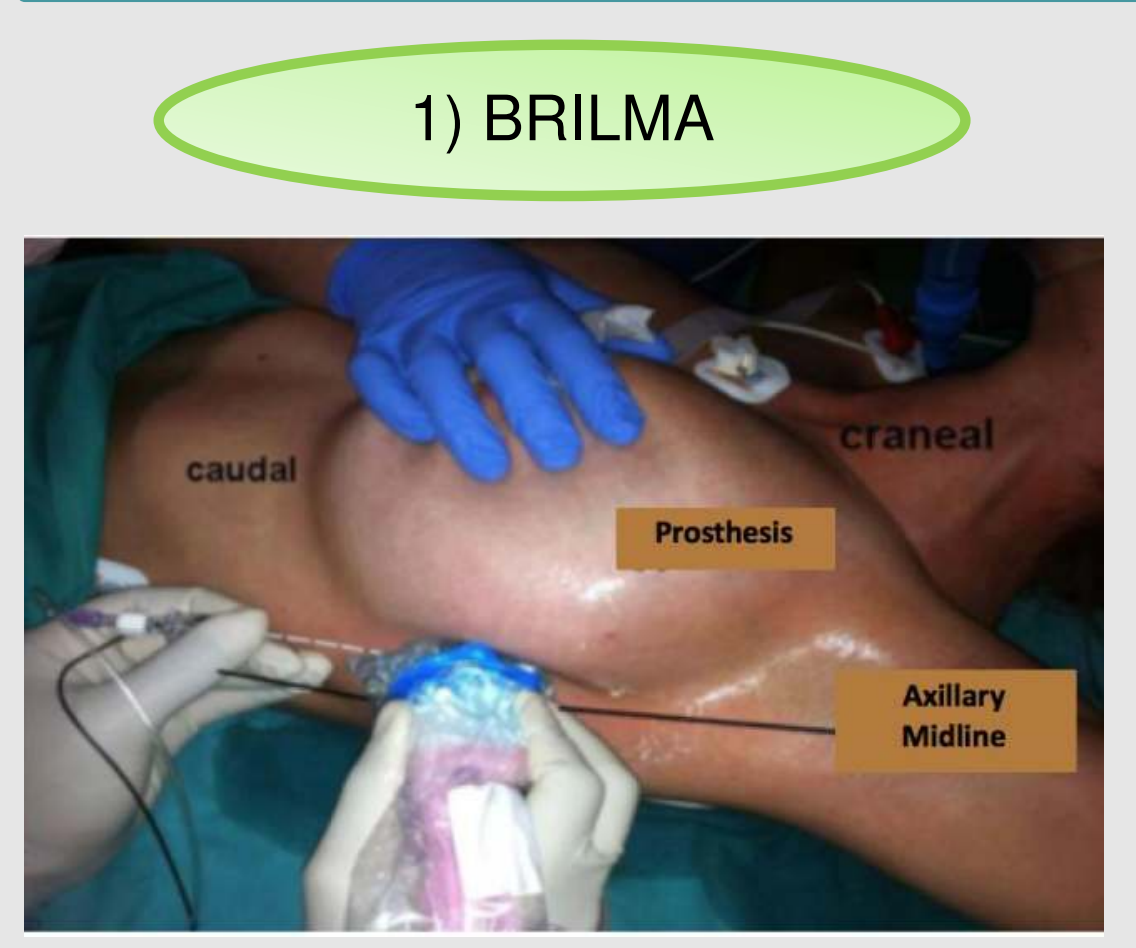

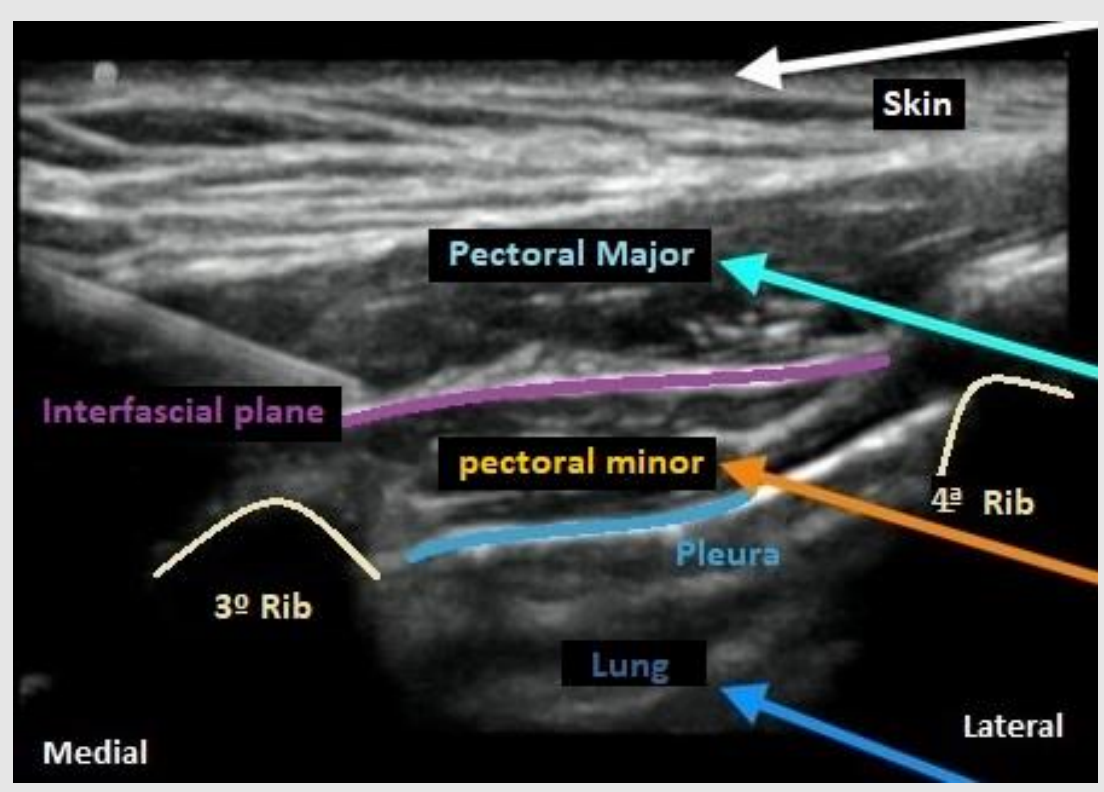

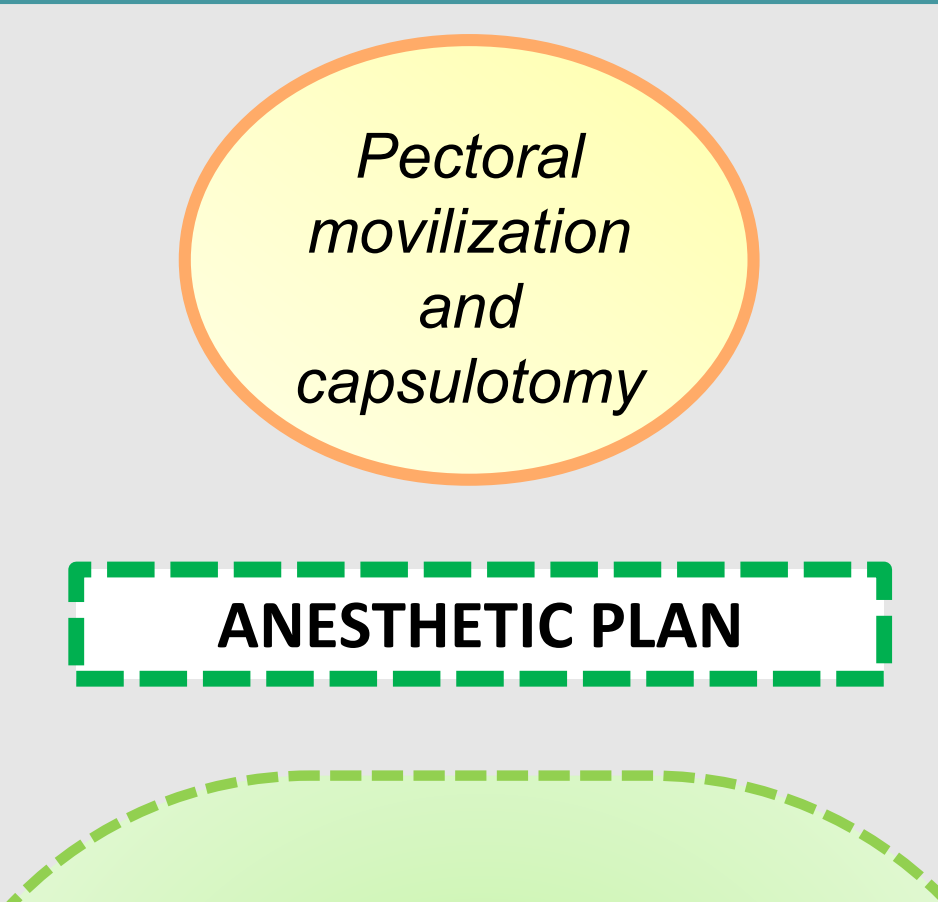

REGIONAL BLOCK AND SEDATION

1) BRILMA:

$10 \times 2 \mathrm{ml} \mathrm{L-Bupi} 0,375 \%$ $10 \times 2 \mathrm{ml}$ Mepi $1 \%$

2) PEC-1: $8 \times 2 \mathrm{ml}$ Mepi 1\%

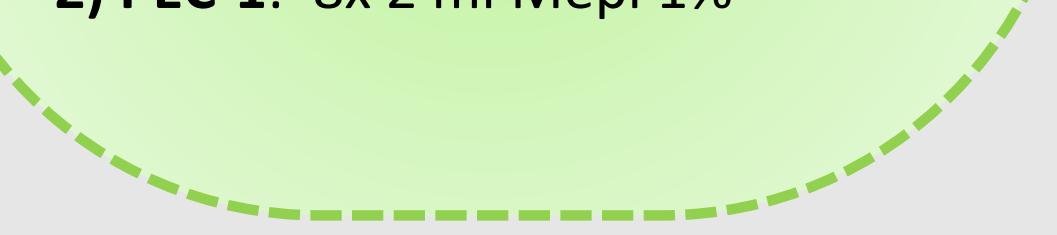

15 minutes Later...
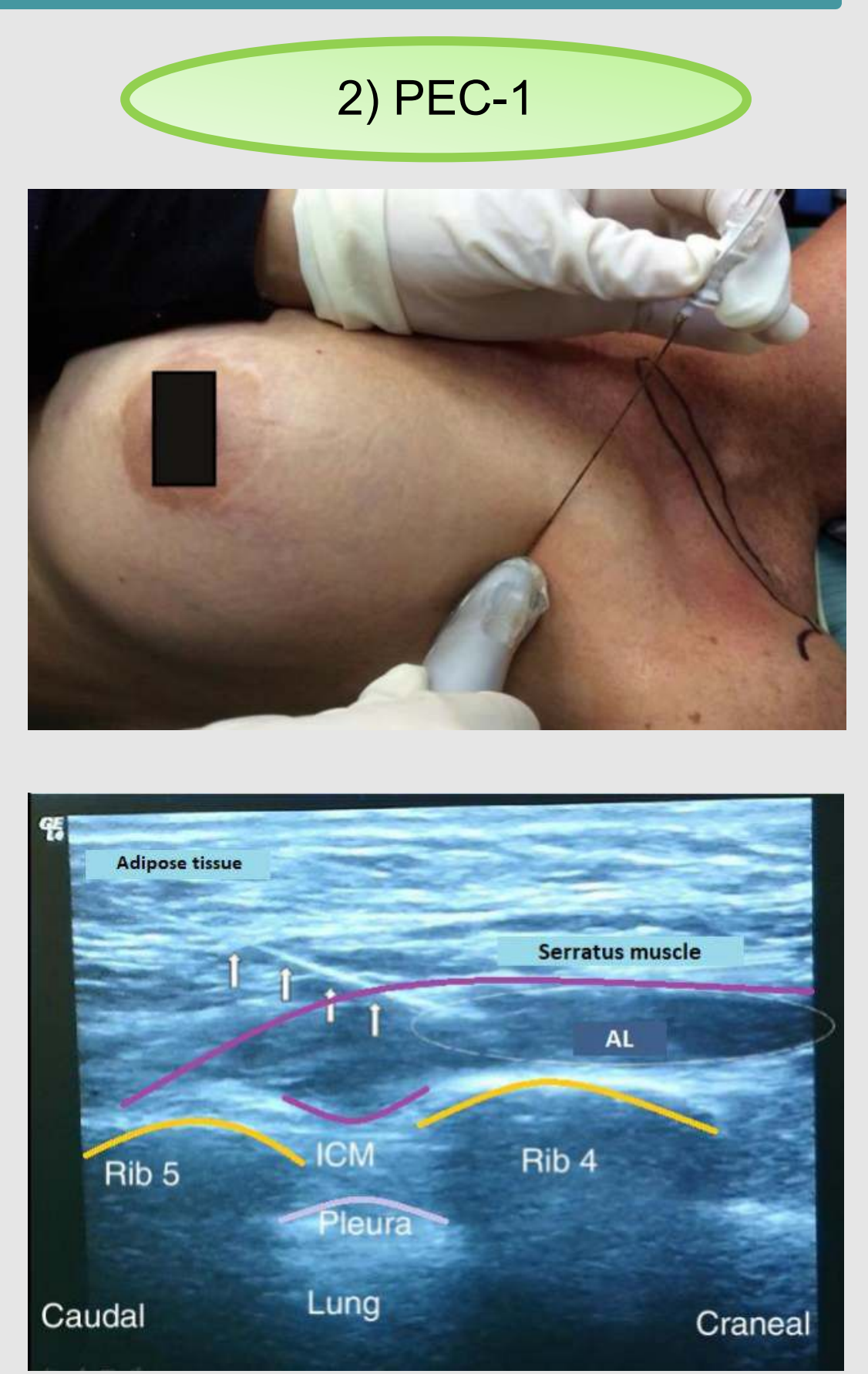

$>$ Incoherent language, dysarthria, involuntary movements $\longrightarrow$ Neurotoxicity

Cardiac toxicity

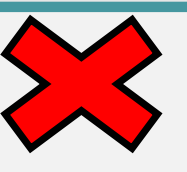

$>$ We suspected LAST so we began treatment with intravenous lipid emulsion and supportive measures (intubation and mechanical ventilation) + Continous cardiac and respiratory monitorization in ICU.

Neurological organic causes were ruled out and TTE showed no new findings. Posterior evolution were satisfactory.

\section{CONCLUSIONS}

I

I.

I

- It should be our priority to establish LAST risk factors sistematically (máximum AL dose or anatomical deformity), moreover in those cases where anesthethic plan is regional.

- Where regional anesthesia is planned, we strongly recommend that more clinical trials should be made to compare the benefits and side efects of those type of blocks versus the paravertebral block, considered the gold standard.

Bibliography

1. Fusco P et al. The association between the ultrasound-guided Serratus Plane Block and PECS I Block can represent a valid alternative to conventional anesthesia in breast surgery in a seriously ill patient. Minerva Anestesiol. 2016;82:241-2.

2. Diéguez P et al. Ultrasound guided blocks for breast surgery. Rev Esp Anestesiol Reanim. 2016;63:159-67.

3. A. Loreto Astudillo, I. Daniella Rigo-Righi. Bloqueos de pared torácica bajo visión ecográfica directa en cirugía de mama. Revista Chilena de Anestesia 2014; 43(1):31-38.

4. Images modified from Dolopedia. 